http://www.jfas.info

\title{
SURVEY OF INDOOR ENVIRONMENTAL QUALITY IN UPNM HEALTH CENTER
}

\author{
A. Khairunnisa, S. P. Chew ${ }^{*}$ and M. Alimi \\ Department of Electrical and Electronics, Faculty of Engineering, \\ UniversitiPertahananNasional Malaysia, Sungai Besi Camp, 57000 Kuala Lumpur, Malaysia
}

Published online: 10 September 2017

\begin{abstract}
This work was carried out at the health center as it has very high potential to centralize the patients with diseases related to health problems such as asthma, respiratory and cardiovascular related-disease. The aim of this study is to conduct the survey among the visitors and patients to determine the occupants comfort. The questionnaire survey determined the occupants' perception on the current indoor air quality in the health center. Recommendations have been made to improve the IAQ in the medical center as related to the accepted level of relative humidity, temperature and $\mathrm{CO}_{2}$.
\end{abstract}

Keywords: indoor air quality (IAQ) survey; medical center; thermal comfort.

Author Correspondence, e-mail: sueping@upnm.edu.my

doi: http://dx.doi.org/10.4314/jfas.v9i3s.46

\section{INTRODUCTION}

Indoor Environmental Quality is defined as the characteristic of the indoor air inside a building that is consist of pollutants and thermal concentration which are highly-related to health, comfort and performance of building occupants [1]. To determine the indoor air quality, it involves the monitoring of human exposure to the pollutants, data collection of the air samples and the air flow in the building by computer modelling. Indoor air quality 
parameters can be classified as chemical, biological and physical which include temperature, humidity, air movement, ventilation and particulate matter [2]. Previous research and investigations on air quality particularly indoor air have taken place in different location such as shopping complexes [3], office buildings [4-5] and classrooms [6-7]. There are a few sources of air pollution, whereas it may come from sources from outside the building, equipment, human activities, building components or even the building occupants itself. In addition, pathways, moisture and humidity also contribute to the sources of indoor air pollutants [8].

This research was carried out at the medical center as it has very high potential to centralize the patient with diseases related to health problems such as asthma, respiratory and cardiovascular related-disease. The aim of this study is to conduct survey among the patients and staffs to determine the occupants comfort in the medical center. In [17] found that the indoor air quality in dormitories at universities needs to be improved. The measured $\mathrm{CO}_{2}, \mathrm{SO}_{2}$, and PM10 were beyond the amount stipulated in related standards. The site measurement and questionnaire investigation showed that it was necessary to improve the IAQ of student dormitories which could be done by increasing the ventilation rate.

On the other hand, in [16] investigates the indoor air quality in the underground shopping mall at Chongqing, China. In this study, the relative humidity, temperature and $\mathrm{CO}_{2}$ concentrations were measured. It is revealed that the concentrations of $\mathrm{CO}_{2}$ in some area of the underground shopping mall exceeded $1500 \mathrm{ppm}$. The excessive levels of $\mathrm{CO}_{2}$ could result from high occupancy combined with insufficient ventilation (Yang et al, 2010). People that live in hot tropical region is more comfortable than that live in temperate or climate region [9].

Thermal comfort is the condition of mind that expressed satisfaction with the thermal environment and is assessed by subjective evaluation [10]. Thermal environmental is those characteristics of the environment which affects a person`s heat loss. In body sensations, thermal comfort is sensation of hot, warm, slightly warmer, neutral, slightly cooler, cool and cold. There are six basic factors in determining the thermal comfort of the occupants in the building. The environmental factors divided into 4; air temperature, radiant temperature, air 
velocity and humidity. Meanwhile, the personal (occupants) factors include clothing insulation and their metabolic heat. Public area has become the concern on the comfort survey [11-13].In [15] has evaluated the thermal comfort of the patient ward in Malaysian hospitals using Fanger Model [14].

In [12] has evaluate the indoor air quality (IAQ) of healthcare facilities. The study was conducted at several hospitals that use different type of air conditioning system. The methods used for data collection include questionnaire, individual observation and personal communication. The result showed that the indoor air quality depends on the used air conditioning system. A subjective investigation was conducted with questionnaire survey. A survey conducted by [13] on exploring the preferred temperature on occupants thermal comfort observed that the number of occupants wanted to be "cooler" exceeded considerably these who wanted to be "warmer"; nearly $58 \%$ of the occupants voted for "cooler" while $43 \%$ and $1 \%$ preferred "no change" and "warmer" respectively.

\section{METHODOLOGY}

The thermal comfort of the occupants in building is asses thru the survey and questionnaire. Occupants' surveys offer a means to systematically measure the performance and also provide diagnostic information for building designers and operators [5]. Before starting a comfort survey, there are several points to be considered. It is important to decide which particular group or individuals for the study. First, it is needed to choose the people that need to be survey. In choosing a sample of subjects, it is need to be noted that the people chosen should be familiar with the surroundings and the climate they are living. The health center of NDUM is located in Sungai Besi, Kuala Lumpur. This medical center is operating for 15 hoursfrom $8 \mathrm{am}$ to $11 \mathrm{pm}$ daily. Fig. 1 shows the ventilation system and how the air flows inside the medical center. The red arrow indicates the air intake from 2 main doors in the medical center. All windows are kept closed during this study, which indicated by the Red Cross. The blue arrow indicates the air circulation in the medical center. The waiting area provided with 2 air conditioning and 3 ventilation systems. The air conditioning is located at the wall of the air with height of approximately $1.8 \mathrm{~m}$. In addition, there are 3 wall fans installed at the waiting 
area. This medical center is designed with 2 main doors, but the front door is covered by the reception area which the first entrance before the occupants enter the waiting area. The ventilation system in this waiting area is good because the sliding door is open all the time, but the main door of the lobby is remained closed. Thus, the air in the medical center has a very wide space to circulate. But, the airflow in the treatment rooms, doctors' room and office are limited because all of the windows are also closed with only air conditioners operating at that area.

From the observation, the staff and nurse prefer to sit around the waiting area if there is no task to be done in their respective department. Meanwhile, it also observed that patient and visitors prefer to sit near the pharmacy counter, near the entrance and under the ventilation system. The observation recorded no growth of mould at the wall, ceiling or furniture in the waiting area. 


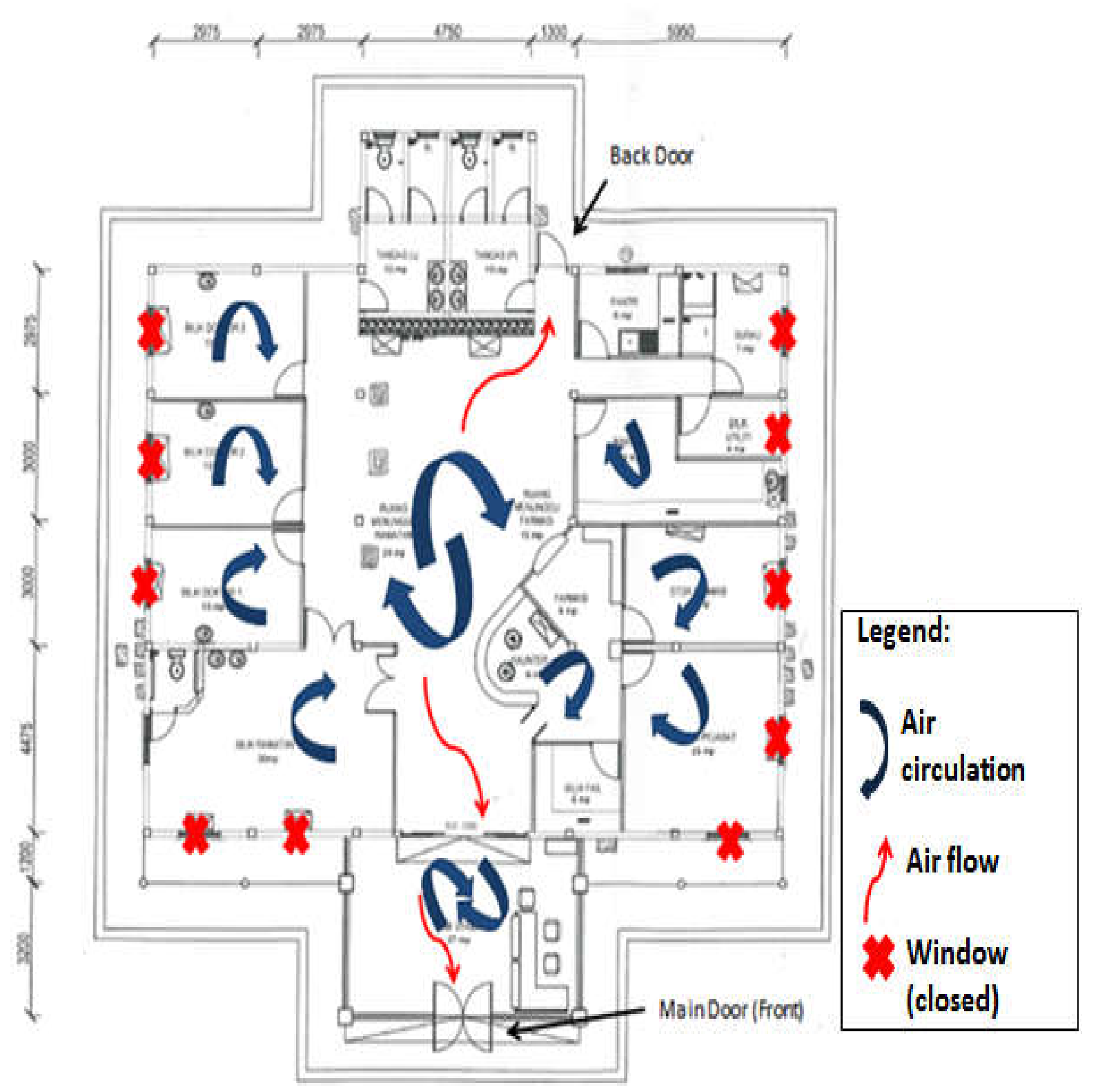

Fig.1. The medical center floor plan including ventilation system

This survey on the thermal comfort in the medical center was conducted among the patients and staffs. The aims of this survey are as following:

1. Identify the demographic of the respondents in terms of their gender, age, category as student, staff or staff family member and how often they visit the medical center.

2. Determine the comfort level of the occupants and visitors, in term of thermal comfort, temperature, air freshness, lighting, furnishing, visual ability and noise level in the medical center.

3. Identify the specific location of the patient to sit and wait for the doctor and their preference area. 
4. Investigate the waiting duration for the respondents have to wait before them able to meet doctor and medicine to be dispensed.

A result from the survey database was obtained from SPSS for analysis. This data comprises 150 occupants in NDUM medical center. The data collected through this survey can be divided up into subjective and objective variable. Objective variables measured include gender, age and occupation. The subjective variables measured include occupant satisfaction and comfort in the building. Occupants in the building are invited to take the survey randomly for over 2 weeks' period. Majority of the responses were collected in the dry season, which Malaysia suffers throughout the year.

\section{RESULTS AND DISCUSSION}

The total number of respondents recruited for the questionnaire survey was 150. Following the removal of cases containing missing values and exclusion criteria, the final sample contain 118 respondents. A summary of respondents' demographic characteristics is presented in Table 1. Most respondents were 18-20 years old (65.3\%), female (58.5\%) and commonly a student (84. 7\%). Majority of the respondents (52.5\%) suffer fever meanwhile $23.7 \%$ suffer flu, $11.9 \%$ suffer cough and others disease as $11 \%$. $61 \%$ respondents state that they visit the medical center within 1-2 times, $31.4 \%$ visits $3-4$ times and $3.4 \%$ for more than 5 visits. Generally, most of the patients are students within age of 18-20 years old,which preference of visiting the medical center for fever (including flu and cough) with the mean of 2 visits within the past six month.

The highest percentage of satisfaction of the indoor air temperature is $18.6 \%$ for neutral, $17.8 \%$ feel slightly satisfied, $16.1 \%$ feel quite satisfied and $13.6 \%$ is satisfied with the indoor air temperature. Patient who does not satisfied with the indoor air temperature is about $33 \%$. Meanwhile, the indoor air freshness gives highest score on patient who satisfied with the IAQ. $26.3 \%$ patient are satisfied with the air freshness, $17.8 \%$ feel neutral, $16.1 \%$ is slightly not satisfied, $12.7 \%$ is quite satisfied, $14.4 \%$ is very satisfied and others are not satisfied with the air freshness. 
Table 1. Demographic characteristic of respondents

\begin{tabular}{|c|c|c|}
\hline Variables & Description & $\mathrm{N}=118$ \\
\hline \multirow[t]{2}{*}{ Gender } & Male & $41.5 \%$ \\
\hline & Female & $58.5 \%$ \\
\hline \multirow[t]{6}{*}{ Age } & $18-20$ & $65.3 \%$ \\
\hline & $21-30$ & $28.0 \%$ \\
\hline & $31-40$ & $4.2 \%$ \\
\hline & $40-50$ & $0.8 \%$ \\
\hline & 51 and above & $1.7 \%$ \\
\hline & Standard Deviation & 0.7695 \\
\hline \multirow[t]{3}{*}{ Category } & Student & $84.7 \%$ \\
\hline & Staff & $11 \%$ \\
\hline & Staff Family Members & $4.2 \%$ \\
\hline \multirow[t]{5}{*}{ Preference } & Fever & $52.5 \%$ \\
\hline & Flu & $23.7 \%$ \\
\hline & Cough & $11.9 \%$ \\
\hline & Others & $11.0 \%$ \\
\hline & Standard Deviation & 2.87 \\
\hline Frequency of & $1-2$ visits & $61.0 \%$ \\
\hline Visiting within past & $3-4$ visits & $31.4 \%$ \\
\hline \multirow[t]{3}{*}{6 months } & $5-6$ visits & $3.4 \%$ \\
\hline & More than 6 visits & $3.4 \%$ \\
\hline & Mean & 1.56 \\
\hline
\end{tabular}

Overall, $47.5 \%$ is satisfied with the indoor air temperature, $18.6 \%$ is feeling neutral about the temperature and only $33 \%$ is not satisfied with the indoor air temperature of the medical center. For the indoor air freshness, $53.4 \%$ is satisfied, $17.8 \%$ is neutral and $28.8 \%$ is not satisfied with the air freshness.

As for the amount of light, most of the patients were satisfied with average 0f $17 \%$ slightly satisfied, quite satisfied and satisfied with that parameter. On the other hand, $10.3 \%$ felt 
neutral, $17.1 \%$ is slightly not satisfied, $6 \%$ is quite satisfied and $13.7 \%$ is not satisfied. For visual comfort, $22.9 \%$ patient is satisfied, $20.3 \%$ is quite satisfied, $18.6 \%$ is slightly satisfied, $11.9 \%$ is neutral, $16.9 \%$ is slightly not satisfied, $5.1 \%$ is quite not satisfied and $3.4 \%$ is not satisfied at all with the visual comfort in the medical center. It can be concluded that $52.1 \%$ is satisfied, $10.3 \%$ is neutral and $36.8 \%$ is not satisfied with the amount of light in the medical center. Meanwhile, $61.8 \%$ is satisfied, $11.9 \%$ is neutral and $25.4 \%$ is not satisfied with the visual comfort in the medical center.

Equipment and facilities in the medical center is divided into 2 parameters, which is furnishing and color and texture of the medical center. $25.4 \%$ patient is slightly satisfied with the furnishing, both quite satisfied and slightly not satisfied are $16.1 \%, 20.3 \%$ is satisfied, $11.9 \%$ is neutral, $2.5 \%$ is quite not satisfied and $6.8 \%$ is not satisfied. More than that, $29.7 \%$ is slightly satisfied with the color and texture of the medical center, $21.2 \%$ is satisfied, $17.8 \%$ is quite satisfied, $14.4 \%$ is slightly not satisfied, $8.5 \%$ is neutral and others is $4.2 \%$. In conclusion, $61.8 \%$ is satisfied with the furnishing provided in the medical center. Only $25.4 \%$ is not satisfied with the furnishing in the medical center. For color and texture of the medical center, about $68.7 \%$ is satisfied. Only $8.5 \%$ respondent feel neutral and $22.8 \%$ feel not satisfied.

For the noise level, $28 \%$ is slightly satisfied, $19.5 \%$ is satisfied, $18.6 \%$ is quite satisfied, $9.3 \%$ neutral, $15.3 \%$ is slightly not satisfied, $5.1 \%$ is not satisfied and $3.4 \%$ is quite not satisfied. As for the sound privacy $25.4 \%$ is slightly satisfied, $21.2 \%$ is quite satisfied, $18.6 \%$ is satisfied, $13.6 \%$ is slightly not satisfied, $10.2 \%$ is neutral and others is $5.1 \%$ and $5.9 \%$ for not satisfied and quite not satisfied. Overall, $66.1 \%$ is satisfied, $23.8 \%$ not satisfied and only $9.3 \%$ is feeling neutral about the noise level in the medical center. Meanwhile, $65.2 \%$ is satisfied with the sound privacy, $10.2 \%$ is feeling neutral and $24.6 \%$ is not satisfied with the sound privacy in the medical center.

Fig. 2 shows the patients satisfaction of the IAQ in the health center. 8 parameters were investigated including the indoor air temperature, indoor air freshness, amount of light, visual comfort, furnishing. color and texture, noise level and sound privacy. All the parameter is divided into 3 categories; temperature and air freshness, lighting and visual, furnishing and 
facilities and noise.

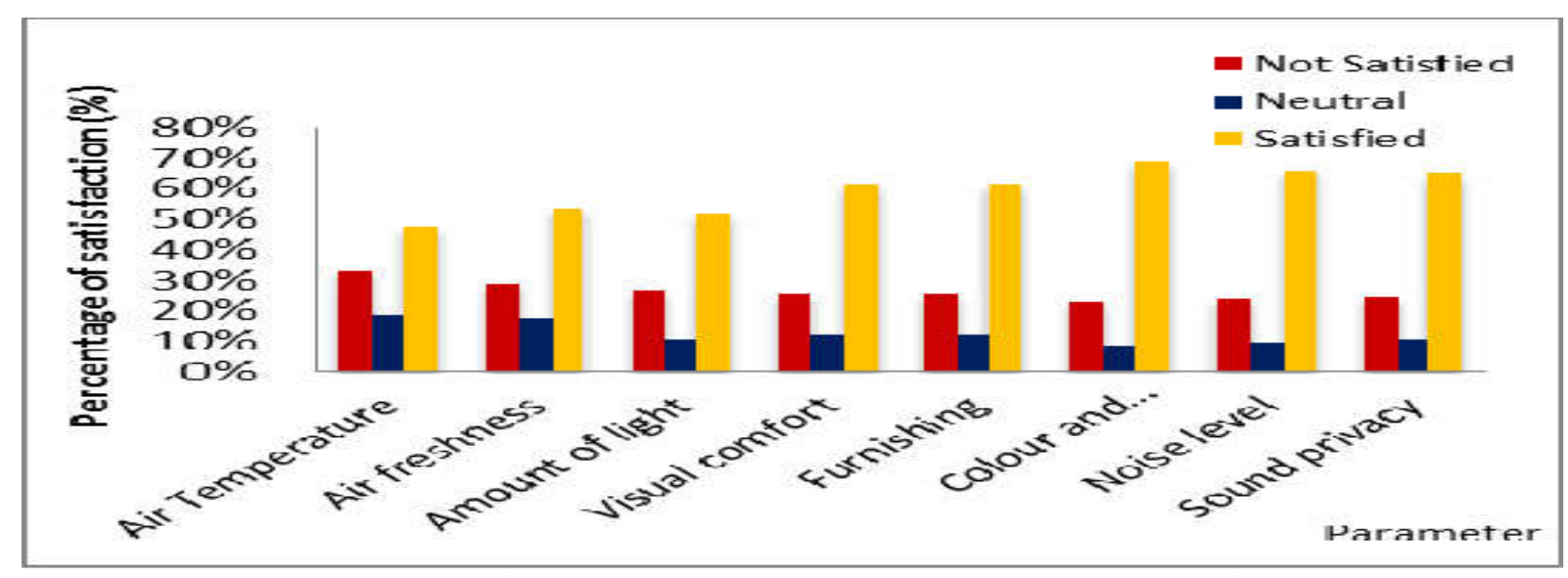

Fig.2. Satisfaction of the IAQ

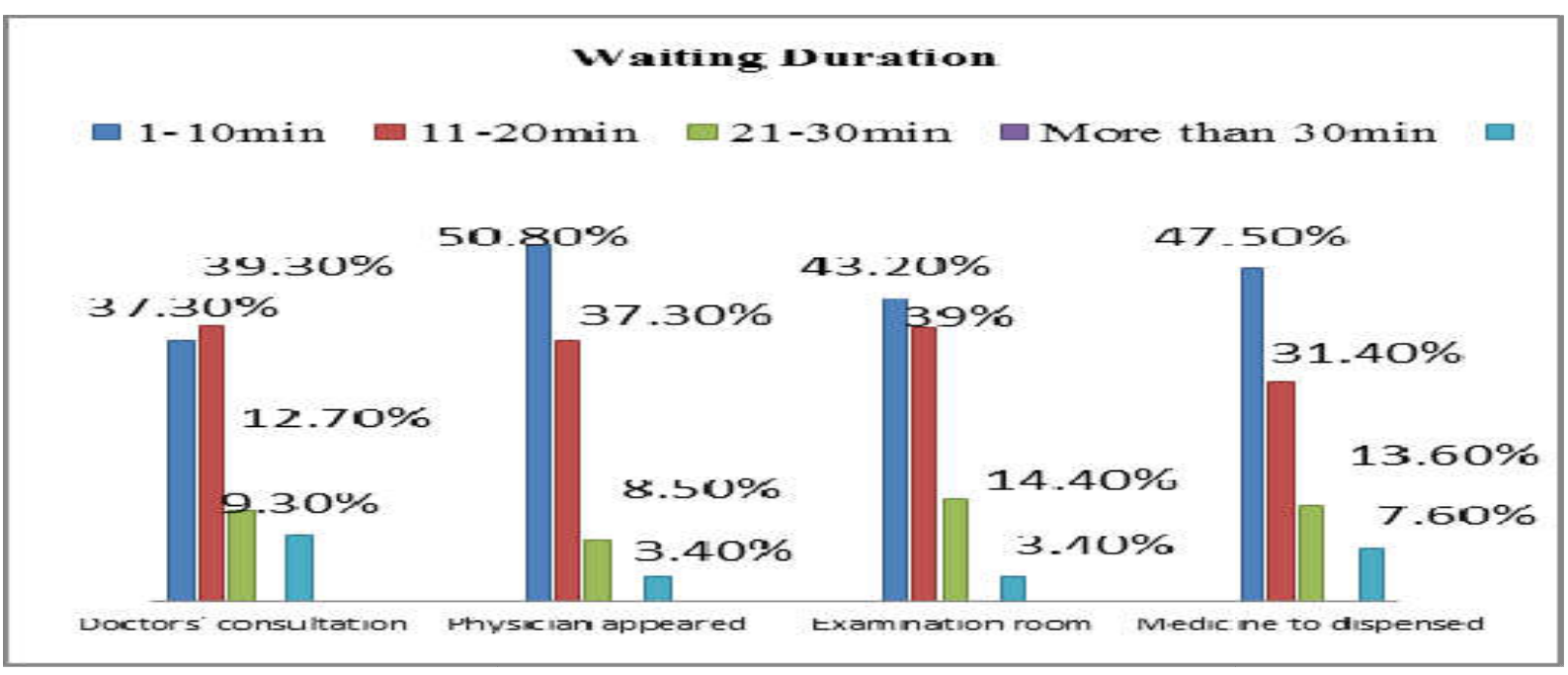

Fig.3. Waiting duration

Out of 118 respondents, almost 40 respondents prefer to sit near the pharmacy counter. Meanwhile, more than 25 respondents sit near the entrance and under the ventilation system. Less than 20 respondents prefer to sit in front of the doctor`s room, 10 respondents sit near the toilet and other location as less than 5. The factor of patient sitting near the pharmacy counter is that, whenever they done with the doctor's consultation, they are waiting for medical dispersed before going home.

Based on this result, it can be concluded that the patients and visitors are prefer to sit at the waiting area.Whereas, the area is concluded near the entrance and under the ventilation system. Based on the survey, it is found that there is high thermal discomfort in the pharmacy. It is due to the decision of the patients and visitor itself to sit near the pharmacy. The 
conclusion that can be made in this findings is that no of occupants in one's area will affect the thermal comforts of the occupants in the building. The more patient sit in that location, it will increase the current temperature of the area. It is suggested that a ventilation system is install in that area, so that patients will feel comfortable while waiting for the medicine dispersion.

When the respondents visit the medical center, their current thermal comfort was assessed. More than 25 respondents feel slightly cool, less than 20 feel cool and cold, 19 respondents feel neutral about the thermal comfort, 22 respondents feel slightly warm and the rest feel warm and hot. The level of comfort-ness in this question is divided into 7 categories; cold, cool, slightly cool, neutral, slightly warm, warm and hot. To categorize the result to cool, neutral and hot, there are 66 respondent feel cool, 19 respondents feel neutral and 33 respondents feel warm. This survey is conducted randomly and the respondent is free to answer the survey whenever they visit the medical center. It can be concluded that the respondents feel comfortable with their current thermal comfort in the medical center.

\section{CONCLUSION}

As the survey was conducted, most of the respondent are within range 18-22 years old, which the students of NDUM itself. Majority of the patient visiting the medical center is due to severe that relates to air quality such as fever, cough and flu. Overall, most respondents satisfied with the air temperature, freshness, lighting, visual comfort, noise and sound privacyexcept the color and texture of the medical center (more on design). They also satisfied with the duration time, where the maximum period of waiting is mainly less than 20 minutes. Most of the visitors select to sit near the pharmacy counter under the air condition and near the entrance. It is believed that this spot provides better air quality and gives comfort to the visitors. As we predicted, almost $50 \%$ of the respondent feel discomfort with the indoor temperature in the afternoon compared to in the morning and evening. This is due to tropical temperature in our country as it hot and shiny in the afternoon. As for the thermal comfort, most of the respondents feel slightly cool, neutral and warm. Therefore, it can be concluded that they are comfortable in the medical center. 


\section{REFERENCES}

[1] Kamaruzzaman S N,Razak R A. Measuring indoor air quality performance in malaysian government kindergarten. Journal of Building Performance, 2011, 2(1):70-79

[2] Behzadi N,Fadey M O. A prelimany study of indoor air qualit conditions in Dubai public elementary schools. Architectural Engineering and Design Management, 2012, 8(3): 192-213

[3] Yang J, K. T. Chan K T, Wu X, Yang X.Investigation of indoor air quality in the underground shopping mall. In IEEE 4th International Conference on Bioinformatics and Biomedical Engineering, 2010, pp. 1-4

[4] Nunes Z G, Martins A S, Altoe A L F, Nishikawa M M, Leite M O, Aguiar P F, Fracalanzza S E. Indoor air microbiological evaluation of offices, hospitals, industries, and shopping centers.Memórias do Instituto Oswaldo Cruz, 2005, 100(4): 351-357

[5] Huizenga C, AbbaszadehS, Zagreus L, Arens E A. Air quality and tehrmal comfort in office buildings: Results of a large indoor environmental quality survey. Proceedings of Health Buildings, 2006, 3: 393-397

[6] Chamberlain B, and Jordan G. Applications of WSN in monitoring indoor air quality in the classroom environment. Denton: University of North Texas, 2012

[7] Fromme H, Twardella D, Dietrich S, Heitmann D, Schierl R, Liebl B. Particulate matter in the indoor air of classrooms-exploratory results from Munich and surrounding area. Atmospheric Environment, 2007, 41(4): 854-866

[8] Ibrahim H A.Indoor air quality in UAE office buildings and their effect on occupants health, comfort, productivity and performance. Master thesis, UAE: The British University in Dubai, 2015

[9] Karyono T H, Sri E, Sulistiawan J G, Triswanti Y. Thermal comfort studies in naturally ventilated buildings in Jakarta, Indonesia. Buildings, 2015, 5(3):917-932

[10] American Society of Heating, Refrigerating, and Air-Conditioning Engineers (ASHRAE). Standard AS 55-2010: Thermal environmental conditions for human occupancy. Atlanta: ASHRAE, 2010

[11] Singh M K, Mahapatra S, Teller J. Study on indoor thermal comfort in the residential buildings of Liege, Belgium. In International Conference on Cleantech for Smart Cities and 
Buildings, 2013, pp. 481-486

[12] Yousef B AA, Elshareef A A D, Ibraheem M A K, Alsayed S S.Assessment of indoor air quality in medical facilities in Sudan. International Journal of Scientific and Technology Research, 2013, 2(1):92-95

[13] Djamila H.Exploring the preferred temperature on occupants thermal comfort in the humid tropics. International Journal of Research in Engineering and Technology, 2014, 3(4):98-102

[14] Mahyuddin N,Awbi H B.A review of $\mathrm{CO}_{2}$ measurement procedures in ventilation research. International Journal of Ventilation, 2012, 10(4):353-370

[15] Azizpour F, Moghimi S, Salleh E, Mat S, Lim C H, Sopian K. Thermal comfort assessment of large-scale hospitals in tropical climates: A case study of University Kebangsaan Malaysia Medical Centre (UKMMC). Energy and Buildings, 2013, 64:317-322

[16] Gao J M, Chen L, Zhang Y, Jin F, Li B Z. Occurrence and pollution source of TVOC in underground stores in Chongqing. Journal of Central South University (Science and Technology), 2012, 11:4554-4558

[17] Sun Y, Zhang Y, Sundell J, Fan Z, Bao L. Dampness at dorm and its associations with allergy and airways infection among college students in China: A cross-sectional study. Indoor Air, 2009, 19(2):174-182

\section{How to cite this article:}

Khairunnisa A, Chew S P, Alimi M. Survey of indoor environmental quality in upnm health center. J. Fundam. Appl. Sci., 2017, 9(3S), 590-601 